\title{
Waste Characterization and Treatment
}

\author{
Edited by William Petruk, Published by the Society for Mining, Metallurgy, and Exploration, Inc., 1998, 162 pp. \\ Paperback , ISBN 0-87335-158-4
}

\section{Reviewed by: S.K. Kawatra}

This book contains the proceedings of the 15th symposium sponsored by the Process Mineralogy Committee of SME. The main focus of the book is the characterization of metallurgical products that can cause environmental problems. The results of the characterizations are then used to solve the respective environmental problem.

Because the book is written by many authors, the style and approach to the various problems changes from chapter to chapter. This provides a good overview of the various approaches and viewpoints in the waste characterization field. Technically, the book is very sound.

The book is divided into the following three sections:

- Section 1: Metal speciation (2 papers).

- Section 2: Characterization of products from mining and metallurgy (7 papers) and

- Section 3: Recycling, characterization and treatment of waste ( 3 papers).

Some of the papers do not really fit into any of the above sections. However, this is to be expected given the logistics of arranging this type of symposium.

The two papers in the first section deal with different topics. The first paper discusses the role of expert witnesses in environmental lawsuits and describes how the courts distinguish between "good science" and "junk science." This is particularly relevant because of the high probability of waste disposal problems leading to legal action. The discussion of how judges must evaluate the validity of technical testimony without any deep understanding of the actual science behind such testimony is especially interesting. The second paper presents a case study of a mercury-contaminated site and follows the process through risk assessment, remediation alternatives and cleanup costs. Methods for determining mercury species in ground water, evaluating the hazard level posed by these species and planning remediation procedures for the site are all discussed in considerable detail.

The second section, which is the main thrust of the book, presents a series of characterization case studies of metallurgical waste products, particularly smelter wastes, arsenic-bearing autoclave wastes, acid-leach residues and mine tailings. The characterization techniques used include $\mathrm{XRD}$, electron microscopy and leachability testing. These results are related to the geochemical behavior of the wastes and are used to assess the environmental risks and treatment costs for these materials.
The third section deals with the viability of metals recycling under changing global environmental restrictions. The main concern presented in the first paper is the growing tendency towards "environmental protectionism," in which the transport of materials classified as toxic across national borders is either heavily restricted or banned. The problem here is that most recycling feedstocks, including metal scrap, are often classified as toxic due to minor alloying elements. Given the difficulty in transporting material for recycle, there is obviously a great incentive to eliminate the production of wastes in the first place or to avoid any need for carrying them across national borders. The remaining two papers take this approach and present a study on the reduction of waste produced by an aluminum smelter and a discussion of the immobilization of toxins in waste materials so that they can be safely disposed of without transporting them for great distances.

Overall, this is a very good book that addresses many of the waste disposal concerns in the minerals industry today. The book explains how proper characterization of the materials can be used to minimize the environmental hazards. Because the book includes a wide range of case studies, it illustrates how apparently minor problems (such as the spillage of mercury from manometers) can give rise to serious problems.

It is important to remember that wastes from particular processes tend to be unique. As a result, it is usually not practical to have a single treatment or recycling process that is applicable to all wastes of a particular type. For waste processing to be as efficient as possible, the process must be carefully adapted to the material to ensure that no toxins are released into the environment while also keeping the process economical. The information in this book provides a great deal of information on the basic characterization methods that can be used for achieving this task.

The book is useful to practicing engineers, who want to know how to use waste characterization to plan treatment and recycling processes, and to researchers, who are carrying out such characterizations. The most valuable feature of the book is the wide range of case studies presented in Section 2. These case studies include descriptions of the original waste, including its source. They then proceed through the characterization steps to determine the nature of the material. This information is then used to evaluate the hazard presented by the waste. Because many types of waste are examined, the methods included in this book are widely relevant.
B.K. Parekh, coauthor of the technical note titled "Effect of various gases on column flotation of fine coal," published in the February 1998 issue (page 48), has advised $M \& M P$ that the wrong authors names were inadvertently used when the paper was originally submitted to SME.
The correct authors should have been: A. Raichur, X.H. Wang and B.K. Parekh. A. Raichur is now with the Indian Institute of Science, Bangalore, India; and X.H. Wang is now group leader with BetzDearborn Paper Process Group, Jacksonville, FL. 